Преводна статия от Европейското списание по болнична фармация, пъбликувана след разрешение на Европейската асоџиаџия на болничните фармацевти (ЕАНР)

\title{
SWITCHING TO DIFFERENT GENERIC MEDICINES: A CHECKLIST FOR SAFETY ISSUES
}

\author{
M. Becker, A. F. Y. Al Hadithy, P. M. L. A. van den Bemt and N. G. Hunfeld \\ Department of Hospital Pharmacy, Erasmus MC, Rotterdam, The Netherlands
}

\section{ПРЕМИНАВАНЕТО КЫМ УПОТРЕБА НА ГЕНЕРИЧНИ ЛЕКАРСТВЕНИ ПРОДУКТИ: КОНТРОЛНА ПРОВЕРКА НА ВЬПРОСИТЕ ЗА БЕЗОПАСНОСТ}

\author{
М. Бекер, А. Ф. Й. Ал Хадити, П. М. Л. А. ван ден Бемт и Н. Г. М. Хунфелд \\ Катедра по болнична фармация, Медииински център към университет „Еразъм“, Ротердам, Нидерландия
}

\begin{abstract}
Резюме. Конкуренцията между предлаганите на пазара генерични лекарствени продукти води до по-ниски цени и намалени разходи за здравеопазване. Въвеждането на нов генеричен продукт обаче би могло да доведе до проблеми с прилагането му в клиничната практика. Ние изготвихме контролна карта със списък въпроси, с помощта на която да се изследват различията между продуктите. Нашата цел с този списък е да установим свойства на алтернативните генерични лекарства, които биха могли да са проблематични при клинична употреба. Навременното предсказване на евентуални проблеми подпомага внимателния подбор и обуславя въвеждането на подходящото генерично лекарство в клиничната практика. В настоящата статия разглеждаме различните позиции в нашата карта и споменаваме за някои от проблемите, които сме срещали през последните няколко години. Вярваме, че с използването на контролната карта болничните фрармацевти ще могат по-добре да правят оптималния избор на генерично лекарство, съответстващо на конкретните изисквания на дадена болница.
\end{abstract}

За повечето лекарства с изтекъл патент, се произвеждат и предлагат в мрежата техни генерични версии. Конкуренцията между предлаганите в снабдителната мрежа генерици води до по-ниски цени и намаляване на разходите за здравеопазване. В нашата болница периодично се подбират доставчици на генерични лекарствени продукти и се сключват договори с тях. В края на всяка година проверяваме договорите, изтичащи следващата година и отправяме искане до производителите за нови оферти за техните продукти за предстоящия период. От тези тръжни предложения избираме лекарствата с найниска цена и най-добро качество.

В процеса на лицензиране и регистриране на генерични лекарствени продукти се прави оценка на еквивалентността на генеричното лекарство с иновативния (оригиналния) продукт, като тази оценка се извършва от съвета за оценка на лекарствата (СНМР). Генериците трябва да отговарят на разпоредбите в Директива 2001/83/ЕО „Кодекс на Общността относно лекарствени продукти за хуманна употреба“" [1]. За небиологични продукти в повечето случаи изпитванията за доказване на биоеквивалентността обикновено са с положителен изход.2 Положението при биологичните продукти е много по-сложно. Въпреки че предлаганите на пазара генерици отговарят на законоустановените критерии, съществуват различия, отделно от разликите в биоеквивалентността, между отделните генерици и иновативните (оригиналните) продукти. Условията на съхранение, ексципиентите и начинът, по който се приготвят парентералните пре- 
парати може да са различни при различните продукти. Понякога тези разлики са едва доловими, но може да са с възможни сериозни последствия за клиничната практика.

В нашата болница имахме няколко случая, при които въвеждането на нов генеричен продукт доведе до проблеми при прилагането в клиничната практика. Лекари и сестри се обърнаха към болничната аптека във връзка с проблемите, които не бяха предвидени преди въвеждането на лекарството. Усилията за разрешаване на тези проблеми са често големи и понякога единственото решение е връщането на продукта, използван преди.

За промяна на тази политика, изразяваща се в действия пост-фактум, ние направихме контролен списьк за изучаване на разликите между продуктите. Позициите в този списьк са опаковка, етикетиране, съдържание на ексципиенти и въпроси, свързани с приготвянето и прилагането. С помощта на този контролен списьк целим да открием характеристики на алтернативните генерици, които потенциално са проблемни при клинична употреба. Идеята е контролният списьк да се използва на етап подбор на алтернативен лекарствен продукт. С попълването на списька може да се предвидят въпроси, които биха могли да предизвикат проблеми при клинична употреба. Тези съображения могат да се вземат предвид в процеса на подбор за предотвратяване на неочаквани проблеми след въвеждането на продукта. Навременното прогнозиране на евентуални проблеми способства внимателния подбор и въвеждането на подходящия генеричен продукт в клиниката. В настоящата статия разглеждаме различните позиции в нашия списък и визираме някои от проблемите, с които сме се сблъсквали през последните няколко години.

\section{ЕТИКЕТИРАНЕ И ОПАКОВКА}

Коректното етикетиране е съществен фактор за правилна употреба на един лекарствен продукт [3]. Мястото, свободно за поставяне на етикети например върху ампули, често е ограничено и понякога текстьт е трудно четим. C вносно лекарство имахме следния проблем: само наименованието на лекарството, използвано в другата държава, фигурираше на ампулите. Нещо повече: концентрацията беше посочена единствено върху кутията, а не и на самите ампули. Наименованието на лекарството не се използваше в нашата страна и лекарите и сестрите не можеха да разпознаят лекарството или да разберат неговата концентрация.

Друг проблем възникна при въвеждането на дексаметазон ампули. Преди това използвахме ампули, изготвени в болничната аптека, но преминахме към промишлено произведен продукт, предлаган в мрежата. На парентералния дексаметазон ампули, изготвени от болничната аптека, беше посочено количеството дексаметазон като дексаметазон динатриев фосфат, а върху нововъведените ампули от мрежата количеството дексаметазон беше посочено като дексаметазон база. За лекарите и сестрите е трудно да се ориентират, че $3.8 \mathrm{mg}$ дексаметазон база е еквивалентно количество на същото използвано като $5 \mathrm{mg}$ дексаметазон динатриев фосфат. Въвеждането на дексаметазон, обозначен като дексаметазон база, няколко пъти доведе до погрешно прилагане на $5 \mathrm{mg}$ дексаметазон база, отговарящ на $6.6 \mathrm{mg}$ дексаметазон динатриев фосфат.

Сходството при етикетирането и опаковките между продуктите на един и същ производител носи риск от объркване на милиграмите или на различните лекарствени продукти на производителя. Тези лекарствени грешки могат да се предотвратят, като се избягват продукти, които си приличат с продукти, вече използвани в клиниката.

\section{УСЛОВИЯ НА СЪХРАНЕНИЕ}

Стандартните условия на съхранение са на стайна температура $\left(15-25^{\circ} \mathrm{C}\right)$, в хладилник $\left(2-8^{\circ} \mathrm{C}\right)$ или в условия на замразяване $\left(-15\right.$ до $\left.-25^{\circ} \mathrm{C}\right)$. Лекарства, които изискват съхранение при различни от изброените условия, са трудни за употреба. Имахме случай с ампули лидокаин-епинефрин, които трябваше да се съхраняват при температура под $15^{\circ} \mathrm{C}$. Възможностите в нашата болнична аптека бяха ампулите да се съхраняват или в хладилник, или на стайна температура. След като получихме допълнителна информация относно стабилността, решихме да съхраняваме ампулите на стайна температура за по-кратък срок на годност.

Сблъскахме се с проблеми, свързани с условията на съхранение и когато сменихме производителя на епинефрин ампули. Преди смяната условията на съхранение на ампулите бяха на стайна температура. Новопоръчаните ампули обаче трябваше да се държат в хладилник. Тъй като епинефринът фигурира и в наборите за спешна помощ, съхранение в условия, различни от стайна температура, беше неподходящо, дори изключено. След като получихме информация за стабилността от производителя, решихме да държим ампулите за наборите за спешна помощ на стайна температура, след като намалихме срока им на годност. Наложи се на ръка да се сменят датите на изтичане на срока на годност върху ампулите. 
Таблица 1. Контролна карта за оценка при избор на генерични продукти

\begin{tabular}{|c|c|c|c|c|}
\hline \multicolumn{3}{|c|}{ Медикамент, начин на приложение (приложения), милиграми strenghts } & \multirow{2}{*}{\begin{tabular}{|l|} 
Номер на артикул \\
Алтернативен продукт 2 \\
\end{tabular}} & \multirow[b]{2}{*}{ Алтернативен продукт 3} \\
\hline & Настоящ продукт & Алтернативен продукт 1 & & \\
\hline \multicolumn{5}{|l|}{ Производител: } \\
\hline \multicolumn{5}{|l|}{ Регистрационен номер: } \\
\hline \multicolumn{5}{|l|}{ Цена } \\
\hline \multicolumn{5}{|l|}{ Изискване } \\
\hline \multicolumn{5}{|l|}{ Наименование и обозначение, пьрвична опаковка } \\
\hline \multicolumn{5}{|l|}{ Наименование и обозначение, вторична опаковка } \\
\hline Етикет с добра четимост & $\mathrm{Aa} / \mathrm{He}$ & $\mathrm{Za} / \mathrm{He}$ & Да/не & $\mathrm{Aa} / \mathrm{He}$ \\
\hline Опаковка & $\begin{array}{l}\text { Единична опаковка/блис- } \\
\text { тер/фллакон ... }\end{array}$ & $\begin{array}{l}\text { Единична опаковка/блистер/ } \\
\text { флакон ... }\end{array}$ & $\begin{array}{l}\text { Единична опаковка/блистер/ } \\
\text { флакон ... }\end{array}$ & $\begin{array}{l}\text { Единична опаковка/блистер/ } \\
\text { флакон ... }\end{array}$ \\
\hline Листовка кьм опаковката на местния език & Да/няма/друг език: ... & Да/няма/друг език: ... & Да/няма/друг език: ... & Да/няма/друг език: ... \\
\hline Условия на съхранение & 15-25 ${ }^{\circ} \mathrm{C} / 2-8^{\circ} \mathrm{C} /$ друго: ... ${ }^{\circ} \mathrm{C}$ & $15-25^{\circ} \mathrm{C} / 2-8^{\circ} \mathrm{C} /$ друго: ... ${ }^{\circ} \mathrm{C}$ & $15-25^{\circ} \mathrm{C} / 2-8^{\circ} \mathrm{C} /$ друго: ... ${ }^{\circ} \mathrm{C}$ & $15-25^{\circ} \mathrm{C} / 2-8^{\circ} \mathrm{C} /$ друго: $\ldots{ }^{\circ} \mathrm{C}$ \\
\hline Срок на годност & ... дни/месеци/години & ... дни/месеци/години & ... дни/месеци/години & ... дни/месеци/години \\
\hline Прикачен етикет & $\mathrm{Aa} / \mathrm{He}$ & $\mathrm{Aa} / \mathrm{He}$ & Да/не & Да/не \\
\hline Баркод на пьрвична опаковка & Линии/матрица/няма & Линии/матрица/няма & Линии/матрица/няма & Линии/матрица/няма \\
\hline Баркод на вторична опаковка & Линии/матрица/няма & Линии/матрица/няма & Линии/матрица/няма & Линии/матрица/няма \\
\hline \multicolumn{5}{|l|}{ Ексципиенти: } \\
\hline глутен & $\mathrm{Za} / \mathrm{He}$ & $\mathrm{Aa} / \mathrm{He}$ & Да/не & $\mathrm{Aa} / \mathrm{He}$ \\
\hline бензилов алкохол & $\mathrm{Aa} / \mathrm{He}$ & $\mathrm{Za} / \mathrm{He}$ & Да/не & $\mathrm{Aa} / \mathrm{He}$ \\
\hline пропилен гликол & $\mathrm{Aa} / \mathrm{He}$ & $\mathrm{Za} / \mathrm{He}$ & Да/не & $\mathrm{Aa} / \mathrm{He}$ \\
\hline етанол & Да/не & Да/не & Да/не & $\mathrm{Aa} / \mathrm{He}$ \\
\hline парабен (E214-E219) & Да/не & Да/не & $\mathrm{Aa} / \mathrm{He}$ & $\mathrm{Aa} / \mathrm{He}$ \\
\hline сулфит (Е220-Е228, метабисулфит) & Да/не & Да/не & $\mathrm{Aa} / \mathrm{He}$ & $\mathrm{Aa} / \mathrm{He}$ \\
\hline пшенично нишесте & $\mathrm{Aa} / \mathrm{He}$ & $\mathrm{Aa} / \mathrm{He}$ & Дa/He & $\mathrm{Aa} / \mathrm{He}$ \\
\hline \multicolumn{5}{|l|}{ други отклоняващи се ексципиенти } \\
\hline \multicolumn{5}{|l|}{$\begin{array}{l}\text { Да се сравнят и двете опаковки (размер, четимост на текста, } \\
\text { риск от дисееренциация на различни милиграми strengths) }\end{array}$} \\
\hline \multicolumn{5}{|l|}{$\begin{array}{l}\text { Да се провери сходността с опаковките, които вече се } \\
\text { използват в клиниката (риск от объркване) }\end{array}$} \\
\hline $\begin{array}{l}\text { Съвместимост с изделията (спринцовки за орално прило- } \\
\text { жение, спейсъри, маншет за вливане под налягане и др.) } \\
\end{array}$ & Изделие: & Изделие: & Изделие: & Изделие: \\
\hline Консултация с лекари & Да/не, с: & Да/не, с: & Да/не, с: & $\mathrm{Aa} / \mathrm{He}, \mathrm{c:}$ \\
\hline Делима ли е таблетката? & Да/не & Да/не & $\mathrm{Aa} / \mathrm{He}$ & $\mathrm{Aa} / \mathrm{He}$ \\
\hline Вкус (за течности за орално приложение) & Няма данни/а именно: & Няма данни/а именно: & Няма данни/а именно: & Няма данни/а именно: \\
\hline \multicolumn{5}{|l|}{ За парентерални препарати: } \\
\hline Позволен пьт на приложение: & $\begin{array}{l}\text { ИВ болус/ИВ вливане/ИМ/ } \\
\text { ПК/ИТ/... }\end{array}$ & $\begin{array}{l}\text { ИВ болус/ИВ вливане/ИM/ } \\
\text { ПК/ИТ/ ... }\end{array}$ & $\begin{array}{l}\text { ИВ болус/ИВ вливане/ИM/ } \\
\text { ПК/ИТ/ ... }\end{array}$ & $\begin{array}{l}\text { ИВ болус/ИВ вливане/ИM/ } \\
\text { ПК/ИТ/ ... }\end{array}$ \\
\hline \multicolumn{5}{|l|}{ Опаковка } \\
\hline \multirow{2}{*}{\multicolumn{5}{|c|}{\begin{tabular}{|l|l|} 
Да се сравнят начините, по които парентералните препа- \\
рати трябва да се приготвят
\end{tabular}}} \\
\hline & & & & \\
\hline Използван разтворител & $\begin{array}{l}\text { ВИ/NaCl 0.9\%/Глюкоза 5\%/ } \\
\text { Включен разтворител/... }\end{array}$ & \begin{tabular}{|l|} 
BИ/NaCl 0.9\%/Глюкоза $5 \% /$ \\
вкпючен разтворител/...
\end{tabular} & $\begin{array}{l}\text { ВИ/NaCl 0.9\%/Глюкоза 5\%/ } \\
\text { включен разтворител/... }\end{array}$ & $\begin{array}{l}\text { BИ/NaCl 0.9\%/Глюкоза 5\%/ } \\
\text { ВКлючен разтворител/... }\end{array}$ \\
\hline Обем след добавяне на разтворител & $\ldots \ldots \mathrm{ml}$ & $\ldots \ldots \mathrm{ml}$ & $\ldots \ldots \mathrm{ml}$ & $\ldots \ldots \mathrm{ml}$ \\
\hline $\begin{array}{l}\text { Обем, концентрация след добавяне на разтворител } \\
\text { (собствен тест) }\end{array}$ & $\ldots . . \mathrm{ml} / \ldots \ldots \mathrm{mg}=\ldots . . \mathrm{Ml}$ & $\ldots . . \mathrm{ml} / \ldots \ldots \mathrm{mg}=\ldots . . \mathrm{Ml}$ & $\ldots \ldots \mathrm{ml} / \ldots \ldots \mathrm{mg}=\ldots . \mathrm{Ml}$ & $\ldots \ldots \mathrm{ml} / \ldots \ldots \mathrm{mg}=\ldots . . \mathrm{Ml}$ \\
\hline осмолалитет & mOsmol/kg & mOsmol/kg & $\mathrm{mOsmol} / \mathrm{kg}$ & $\mathrm{mOsmol} / \mathrm{kg}$ \\
\hline \multicolumn{5}{|l|}{ Забележки } \\
\hline \multicolumn{5}{|l|}{ Извършил оценката: } \\
\hline & & Извършил оценката: & & \\
\hline & & Замяната одобрена: да/не & & \\
\hline & & Одобрено от: & & \\
\hline
\end{tabular}

\section{ЕКСЦИПИЕНТИ/ПОМОЩНИ ВЕЩЕСТВА}

За повечето продукти използваните помощни вещества/ексципиентите не играят важна роля и често биват пренебрегвани. В някои случаи обаче различията при ексципиентите могат да имат сериозно значение. През 2010 г. направихме замяна на гемцитабинови продукти. Едно от предимствата беше, че преминахме от „прах за инжекционен разтвор“ към „инфузионен концентрат“, което улесни процедура- та за приготвяне на гемцитабин за директно приложение. Скоро след въвеждането на новия продукт получихме оплаквания от пациенти, че се чувствали пияни след приемане на гемцитабин. Новият продукт съдържаше етанол като разтворител. С всеки грам гемцитабин са били давани и $11 \mathrm{~g}$ етилов алкохол. За човек с тегло $70 \mathrm{~kg}$, приемащ $1000 \mathrm{mg} / \mathrm{m}^{2}$ гемцитабин, приетият алкохол отговаря на две чаши бира. Преценихме, че това количество алкохол е неприемливо и заменихме продукта с друг. 
Други проблеми възникват с продукти, съдържащи бензилов алкохол като консервант. При малките деца бензиловият алкохол не се метаболизира и ако приетото количество е твърде голямо, се натрупва бензоена киселина. Тъй като метаболитьт е невротоксичен, прилагането на този консервант на деца до тригодишна възраст е противопоказно. Също така често се използва пропилен гликол за разтворител и при възрастни рискът от интоксикация е ограничен. Малките деца обаче метаболизират пропилен гликола по-бързо, което носи риск от настьпване на метаболитна ацидоза. Поради тази причина дневна доза над $200 \mathrm{mg} / \mathrm{kg}$ е противопоказна при деца.

\section{Съвместимост}

За прилагане на лекарствата се използват найразлични системи, като набори за вливания за парентерални разтвори и инхалаторни системи за лекарства за дихателната система. Очевидно е, че тези системи следва да са съвместими с новия генеричен продукт. Срещали сме обаче трудности след въвеждането на флакони човешки имуноглобулини. Отворчето на флакона беше толкова малко, че след вкарване на спайка, не остава място за игла с клапа. Наложи се да въвеждаме нова инфузионна система, окомплектована със спайк и игла с клапа, за прилагането на нововъведените имуноглобулини.

\section{ПРИГОТВЯНЕ НА ЛЕКАРСТВА ЗА ПАРЕНТЕРАЛНО ПРИЛОЖЕНИЕ}

Други важни выпроси касаят различията в начина на приготвяне на парентерални лекарства. Например различия в концентрацията на дадено лекарство могат да доведат до предозиране или недостатьчно дозиране. При лекарства с мальк терапевтичен прозорец, като например онкопродуктите, последствията могат да бъдат много сериозни. С въвеждането на друга генерична версия е задължително да се направи своевременно преглед и актуализиране на всички протоколи винаги, когато заменящият препарат изисква промени. Въвеждането на нов генеричен продукт неотменно трябва да се съпьтства от едновременно изтегляне на варианта, използван преди. В нашата болница винаги сме проверявали тези выпроси обстойно преди съответното въвеждане и не са се случвали подобни грешки.

\section{БИОПОДОБНИ ЛЕКАРСТВА}

С помощта на нашата контролна карта е възможно да се предвидят болшинството проблеми, които биха могли да настьпят след въвеждането на нов генеричен продукт. Елементите в нашия контролен списьк са замислени специално за генерици с малки молекули.
Обаче поради факта, че много фини и малки различия при генеричните макромолекулярни биологични (биоподобни) лекарствени продукти могат да имат сериозни евентуални последствия, е възможно да възникнат други выпроси, непосочени в този списьк. Затова сравняването на един биоподобен продукт с друг такъв или със съответните патентовани продукти трябва да е по-обстойно, както е онагледено с казуса с интравенозните имуноглобулини (ИВИГ).

\section{КАЗУСът С ИВИГ}

ИВИГ са силно пречистени антитела, срещащи се в природата, които са получени от човешка плазма.3 Изолирането и пречистването на ИВИГ от човешка плазма представлява сложен и изменчив процес, при който се наблюдават значителни вариации както между различните ИВИГ, така и между отделните партиди. По-долу се разглеждат два ключови въпроса, свързани с безопасността. Тези въпроси показват, че сравняването между биоподобни лекарствени продукти е много по-сложно и включва аспекти, характерни за конкретния продукт, които не могат да бъдат обхванати в един универсален списък.

\section{ЗАМЪРСЯВАНЕ С ИНФЕКЦИОЗНИ АГЕНТИ}

Бивайки по същество продукт от сборна плазма, получена от хиляди пациенти, ИВИГ могат да пренасят инфекциозни болести. Задължително се прави подбор на донорите, скрининг на събрания материал, пречистване и вирусна инактивация за елиминиране на риска от възможно замърсяване [4]. За допълнително гарантиране на максимална безопасност на продукта ИВИГ се извличат от сборна плазма от хиляди донори (плазменият пул може да включва от 1000 до 60000 души) [5]. Въпреки че големият брой донори увеличава вероятността от предаване на инфекция, той в същото време намалява дозата на който и да било инфекциозен агент, неотстранен в процесите на подбор на донорите и на пречистване. 3 Прилаганите в момента процедури за отстраняване на вируси (напр. студово фракциониране на етанол, инкубация при ниски стойности на $\mathrm{pH}$ и нанофилтрация) се различават в своята ефективност срещу капсулирани (напр. HIV, вируси на хепатит B и C) и некапсулирани вируси (напр. хепатит А и паровирус В19). За подбора на безопасни ИВИГ болничните фармацевти трябва да извьршват верификация на ефективността на прилаганите в хода на производството процедури по пречистване и отстраняване на вируси, тъй като тези стыпки може да са различни при различните ИВИГ, предлагани на пазара. Значимостта на този въпрос беше демонстрирана през 1994 г., когато Цен- 
търьт за контрол на заболяванията на САЩ (the US Center for Disease Control) документира повече от 100 докладвани случая, касаещи предаване на хепатит $\mathrm{C}$ посредством прилагане на ИВИГ, довели до изтегляне на някои продукти ИВИГ от пазара [3].

\section{РИСКЪТ ОТ СЛУЧАИ НА ТРОМБОЕМБОЛИЯ}

Връзката между ИВИГ и случаи на тромбоемболия (СТЕ) е наблюдавана преди повече от 25 години [3]. Смъртността при СТЕ е 20\%, най-често са с артериален произход и може да включват инсулт, инфаркт на миокарда и белодробна емболия. Честота на СТЕ е 0.6-3\% (пациент или 0.2-1.2\%)курс на лечение.5 Един от предложените преди механизми е рязкото увеличение на вискозитета на плазмата поради голямото белтъчно натоварване от ИВИГ.3 5 Внезапното повишение на вискозитета може да увеличи съсирването, да предизвика вазоспазьм или да наруши сьдовото саморегулиране така, че е възможно да настыпи артериална тромбоза. Скорошни открития обаче дават основание да се счита, че евентуалният механизъм е друг: замърсяване със съсирващи фактори. Фактически германските и шведските власти отмениха разрешението за употреба за един от продуктите ИВИГ поради неприемливо висока честота на СТЕ $[6,7]$. Проблемът на СТЕ беше отдаден на възможно ненадлежно пречистване в производствения процес, довело до замърсяване с фактор ХІа при някои партиди $[6,7]$. При все че рискът от замърсяване с фактори, увеличаващи съсирването, привлече интерес напоследьк, $[7,8]$ следва да се отбележи, че този проблем е установен десетилетия преди този случай $[9,10]$. Поради това е възможно да се очакват различия между разнообразните продукти ИВИГ, когато един продукт се заменя с друг.

\section{ЗАКЛЮЧЕНИЯ}

Преминаването към генерични лекарствени продукти с най-ниска цена намалява разходите за лекарства в болниците. Ако обаче замяната не се извърши правилно, може да възникнат проблеми или рискове в клиничното им прилагане. Ние създадохме контролна карта със списък за установяване и предотвратяване на възможни проблеми, които биха могли да настыпят при замени с генерични лекарствени продукти. Както обаче се опитахме да покажем с ИВИГ, при макромолекулярни биологични продукти може да има специфични въпроси (напр. свьрзани с пречистеността и безопасността), които правят предложения списьк по-малко приложим при подбор на такива продукти. Вярваме, че с помощта на този контролен списьк болничните фар- мацевти ще могат по-добре да правят най-удачния избор на генеричен лекарствен продукт съобразно изискванията на конкретното лечебно заведение.

Благодарности: Бихме желали да благодарим на проф. А Г Вулто (Professor AG Vulto) за това, че предложи тематиката на настоящата статия и за неговата помощ при написването й.

Принос: Всички автори допринесоха в еднаква степен за разработването на настоящата статия.

Конкуриращи се интереси: Няма.

\section{БИБЛИОГРАФИЯ}

1. Directive 2001/83/EC. Community code relating to medicinal products for human use, March 2010. http://europa. eu/legislation_summaries/internal_market/single_market_ for_goods/pharmaceutical_and_cosmetic_products/121230_ en. $\overline{h t m}$ (accessed 6 sep 2012)

2. European Medicines Agency. Guideline on the investigation of bioequivalence, March 2010. http://www.emea. europa.eu/docs/en_GB/document_library/Scientific_guideline/2010/01/WC500070039.pdf (accessed 6 sep 2012)

3. Caress JB, Kennedy BL, Eickman KD. Safety of intravenous immunoglobulin treatment. Expert Opin Drug Saf 2010;9:971-9.

4. European Medicines Agency. Guideline on the clinical investigation of human normal immunoglobulin for intravenous administration (IVIg), (March 2010). http:// www.ema. europa.eu/docs/en_GB/document_library/Scientific_guideline/2010/03/ WC500078472.pdf (accessed 6 sep 2012)

5. Gürcan HM, Keskin DB, Ahmed AR. Information for healthcare providers on general features of IGIV with emphasis on differences between commercially available products. Autoimmun Rev 2010;9:553-9.

6. European Medicines Agency. Questions and answers on the recommendation to lift the suspension of Octagam (human normal immunoglobulin 5\% and 10\%), March 2010. http://www.ema. europa.eu/docs/en GB/document library/ Referrals document/ Octagam_31/WC 500105245.pdf (accessed 6 sep 2012)

7. Roemisch JR, Kaar W, Zoechling A, et al. Identification of activated FXI as the major biochemical root cause in IVIG batches associated with thromboembolic events. Analytical and experimental approaches resulting in corrective and preventive measures implemented into the Octagam manufacturing process. Webmed Cent Immunother 2011;2:WMC002002.

8. Etscheid M, Breitner-Ruddock S, Gross S, et al. Identification of kallikrein and FXIa as impurities in therapeutic immunoglobulins: implications for the safety and control of intravenous blood products. Vox Sang 2012;102:40-6.

9. Alving BM, Tankersley DL, Mason BL, et al. Contact-activated factors: contaminants of immunoglobulins preparations with coagulant and vasoactive properties. J Lab Clin Med 1980;96:334-46.

10. Wolberg AS, Kon RH, Monroe DM, et al. Coagulation factor $\mathrm{XI}$ is a contaminant in intravenous immunoglobulin preparations. Am J Hematol 2000;65:30-4.

\author{
Адрес за кореспонденция: \\ Dr Matthijs L Becker \\ Department of Hospital Pharmacy \\ Erasmus MC \\ PO Box 2040 \\ Rotterdam 3000CA \\ The Netherlands \\ m.becker@erasmusmc.nlm.becker@erasmusmc.nl
}

